\title{
Experimental and Simulation Analysis of Physical Water Model through Tracer Injection under Various Baffles and Turbulence Inhibitor Conditions for Developing the Fluid Flow Parameters and Inclusion Removal Rates in Tundish
}

\author{
Jaywant Namdev Yadav ${ }^{1, *}$ (D), Netra Pal Singh 1 (D) \\ 1 Department of Mechanical Engineering, Oriental University, Indore 453555, MP-India \\ * Correspondence: jny.hydro@gmail.com (J.N.Y.);
}

Received: 24.08.2021; Revised: 20.10.2021; Accepted: 24.10.2021; Published: 18.11.2021

Abstract: Tundish is a critical part involved in the continuous casting process, which ensures the constant flow of liquid metal and with performing different functions. In odd-numbered multistrand tundish, the confirmation consistency of the fluid flow among all the strands is one of major concerns. In this study, five-strand tundish with a set of weirs and a baffle is utilized for investigation concerning fluid flow parameters and inclusion removal analysis. The simulation is carried out in ANSYS FLUENT 19.2 software through the defined numerical model, and the experimental analysis is performed on a scaled physical water model through tracer injection. Four different baffles are designed along with two different types of turbulence inhibiter for the tundish to enhance the fluid flow parameters and inclusion removal rates. The inclusion sizes were varied from 10 to $100 \mu \mathrm{m}$ with a difference of $20 \mu \mathrm{m}$ respectively for studying the inclusion removal rate concerning inclusion sizes. From the outcomes obtained like the residence time distribution (RTD) curves and others, it was concluded that the fourth baffle version with the first turbulence inhibiter, which are equipped in tundish version TV8 is the most beneficial tundish version for the enhancement in fluid flow and inclusion removal rates as compared to other tundish versions in this study.

Keywords: CFD analysis; physical water model; residence time distribution analysis (RTD); multistrand tundish; baffles; turbulence inhibiters.

(C) 2021 by the authors. This article is an open-access article distributed under the terms and conditions of the Creative Commons Attribution (CC BY) license (https://creativecommons.org/licenses/by/4.0/).

\section{Terminology}

\begin{tabular}{c|l|l} 
Symbols & Description & Units \\
\hline $\mathbf{k}$ & Turbulence kinetic energy & $\mathrm{m}^{2} / \mathrm{S}^{2}$ \\
\hline $\boldsymbol{\varepsilon}$ & Turbulence eddy dissipation & $\mathrm{m}^{2} / \mathrm{S}^{3}$ \\
\hline $\mathbf{P}$ & Pressure & $\mathrm{Pa}$ \\
\hline $\boldsymbol{\rho}$ & Density of steel & $\mathrm{Kg} / \mathrm{m}^{3}$ \\
\hline $\boldsymbol{\rho}_{\mathbf{p}}$ & Density of the particle & $\mathrm{Kg} / \mathrm{m}^{3}$ \\
\hline $\boldsymbol{\sigma}_{\mathbf{k}}$ & Constant for $\mathbf{k} \boldsymbol{\boldsymbol { \varepsilon }}$ turbulence model & \\
\hline $\boldsymbol{\sigma}_{\boldsymbol{\varepsilon}}$ & Constant for $\mathbf{k} \boldsymbol{\boldsymbol { \varepsilon }}$ turbulence model & \\
\hline $\boldsymbol{\mu}_{\mathbf{t}}$ & Turbulent viscosity & $\mathrm{Pa} . \mathrm{S}$ \\
\hline $\boldsymbol{\mu}_{\mathbf{e f f}}$ & Effective viscosity & $\mathrm{Pa} . \mathrm{S}$ \\
\hline$\overline{\mathbf{S}_{\mathbf{N}}}$ & Total average standard deviation at each strand & \\
\hline $\boldsymbol{\sigma}_{\mathbf{i}}^{2}$ & Variance & \\
\hline $\mathbf{T}_{\mathbf{a}}$ & Total average residence time & $\mathrm{S}$ \\
\hline$\overline{\mathbf{T}_{\mathbf{a}}}$ & Average residence time at each strand & $\mathrm{S}$
\end{tabular}




\begin{tabular}{|c|c|c|}
\hline Symbols & Description & Units \\
\hline$\Delta \mathbf{t}_{\mathbf{i}}$ & Time interval & $\mathrm{S}$ \\
\hline $\mathbf{t}_{\mathbf{i}}$ & Sampling time & $\mathrm{S}$ \\
\hline $\mathbf{C}_{\mathbf{i}}$ & Concentration of tracer at $\mathbf{t}_{\mathbf{i}}$ & \\
\hline $\mathbf{R e}_{\mathbf{p}}$ & Reynolds number of inclusions & \\
\hline$\Delta$ & Apparent wall roughness & $\mathrm{m}$ \\
\hline g & Gravitational acceleration & $\mathrm{m} / \mathrm{s}^{2}$ \\
\hline $\mathbf{u}_{\mathbf{i}}$ & Fluid velocity at i direction & $\mathrm{m} / \mathrm{s}$ \\
\hline $\mathbf{c}_{\mu}$ & Constant for $\mathbf{k}-\boldsymbol{\varepsilon}$ turbulence model & \\
\hline $\mathrm{C}_{1 \varepsilon}$ & Constant for $\mathbf{k}-\boldsymbol{\varepsilon}$ turbulence model & \\
\hline $\mathrm{C}_{2 \varepsilon}$ & Constant for $\mathbf{k}-\boldsymbol{\varepsilon}$ turbulence model & \\
\hline$D_{\text {eff }}$ & Effective diffusivity & $\mathrm{m}^{2} / \mathrm{s}$ \\
\hline $\mathbf{u}_{\mathrm{pi}}$ & Particle velocity at i direction & $\mathrm{m} / \mathrm{s}$ \\
\hline$\tau_{\mathbf{p}}$ & Relaxation time & $\mathrm{S}$ \\
\hline$\tau_{\mathbf{w}}$ & Shear force & $\mathrm{Pa}$ \\
\hline$\tau_{\text {critical }}$ & Critical fluid shear force & $\mathrm{Pa}$ \\
\hline $\mathbf{P}_{\mathbf{a}}$ & Probability of inclusion adsorption & \\
\hline$\xi$ & Random number & \\
\hline A & Hamaker number & \\
\hline $\mathbf{h}$ & Constant spacing of Van der Waals force & $\mu \mathrm{m}$ \\
\hline$T_{r}$ & Response time & $\mathrm{S}$ \\
\hline $\mathbf{T}_{\mathbf{p}}$ & Peak time & $\mathrm{S}$ \\
\hline $\mathbf{V}_{\mathbf{p}}$ & Volume ratio of plug zone & - \\
\hline $\mathbf{V}_{\mathbf{p i}}$ & Volume ratio of plug zone at $(\mathrm{i})^{\text {th }}$ strand & - \\
\hline $\mathbf{V}_{\mathbf{d}}$ & Volume ratio of the dead zone & - \\
\hline $\mathbf{V}_{\mathrm{di}}$ & Volume ratio of the dead zone at $(\mathrm{i})^{\text {th }}$ strand & - \\
\hline $\mathbf{V}_{\mathrm{m}}$ & Volume ratio of the well-mixed zone & - \\
\hline $\mathbf{V}_{\mathbf{m i}}$ & Volume ratio of the well-mixed zone at $(\mathrm{i})^{\text {th }}$ strand & - \\
\hline
\end{tabular}

\section{Introduction}

The tundish is the critical part of the continuous casting process, which requires the proper design as the quality of the steel produced depends on it. Tundish is a shallow vessel, which comprises secondary or sometimes primary purification of the steel. The major function of the tundish is maintaining the constant flow of the liquid metal in the molds. The tundish type can be classified concerning shape, size, several strands, lining material, type of strands, etc. The tundish investigated in this study is odd number (five) multistrand tundish, which is shown with dimensions in Fig.1. This tundish comprises five outlets and on the inlet with a baffle, set of weirs, and a turbulence inhibiter. The fluid flow parameters and inclusion removal rate of the tundish are investigated through finite element simulation and validated through a scaled physical water model experiment. The consistency of the fluid flow among all the strands is also investigated by studying the residence time distribution (RTD) curves and inclusion removal rates. The computational fluid dynamic (CFD) simulation is carried out in the ANSYS FLUENT 19.2 software commercial package. Four different types of baffles and two different turbulence inhibitors (TIs) are developed and applied in the tundish, and their effect on the fluid flow and inclusion removal is studied. Researchers have performed an investigation on the multistrand tundish with five strands concerning the fluid flow pattern, inclusion removal, and temperature distribution analysis. There are four different types of baffles, and two different types of turbulence inhibitors (TIs) are developed for enhancing the fluid flow pattern, reducing the short-circuiting of the fluid flow, increasing peak and residence time, and reducing the volume of the dead zone and increasing the volume of plug zone and also for confirming the consistency of flow in all the strands. The flow parameters and 
residence time distribution (RTD) curves obtained from the simulation are validated with the scaled water model experimental analysis. The results obtained from simulation and experimental analysis were in good agreement with each other. It is discovered that there is an increase in residence time and volume of plug zone and a decrease in dead zone formation after the application of developed baffles and TIs. The inclusion removal rate increases with an increase in the inclusion sizes, and the developed baffles and TIs also improved the inclusion removal rate in the tundish. It was finally concluded that there was a consistency improvement in each strand after applying the developed baffles and TIs [1-16].

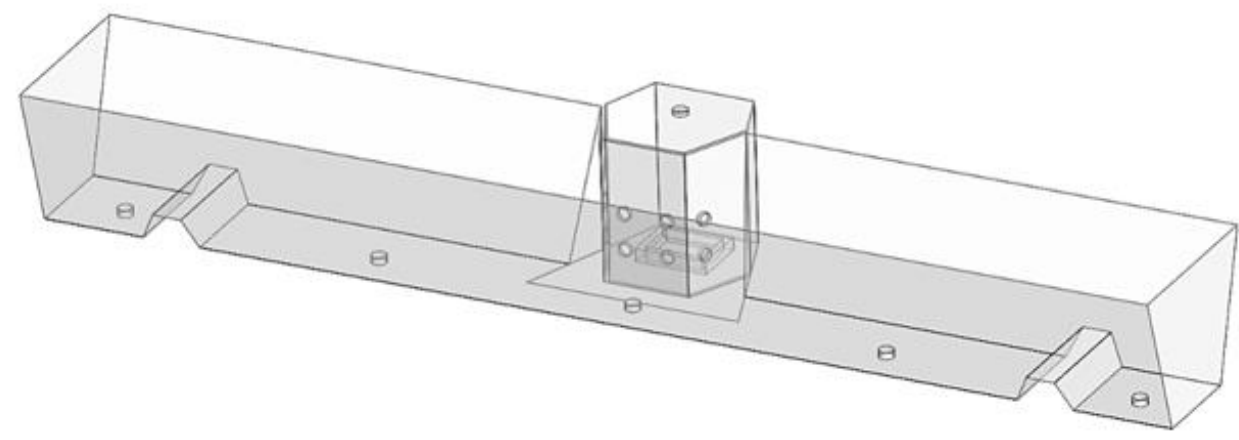

Fig.a

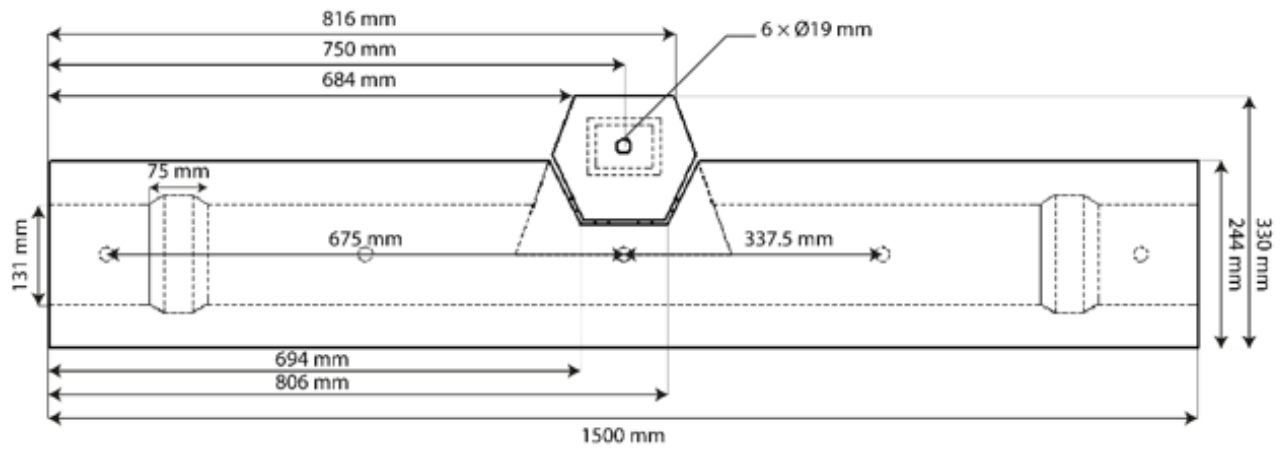

Fig.b

Figure 1. Tundish 3D model (a) actual view and (b) top view with dimensions.

In a study, researchers have investigated the fluid flow, temperature distribution, and inclusion removal in a tundish utilized in continuous casting. The different types of flow modifiers were deployed for enhancing the fluid flow parameter, which were dams and weirs. A computation model was developed for investigating these parameters and validate with experimental testing. The ANSYS CFX software was utilized to simulate the computational model based on the element-based finite volume method (EbFVM). The turbulent fluid flow and temperature distribution were evaluated through the EbFVM. The method used for inclusion generation was random nucleation mechanism, and for evaluating the turbulence of the inclusion, a modified Lagrangian model with a random walking model (RWM) is utilized. It was concluded that this model could be utilized for evaluating the fluid flow, temperature distribution, and inclusion removal parameters of the other tundish configurations [3, 17-23].

Researchers have conducted fluid flow analysis of the single strand tundish with different flow control devices. The computational fluid dynamic analysis is carried out in ANSYS 14.0 and validated experimentally with a physical water model. The turbulent fluid 
flow is presented through the k- $\varepsilon$ equation. The residence time distribution (RTD) curves were obtained through tracer concentration. The flow modifiers extensively affect the fluid flow and improve the residence time, and improve the inclusion removal rate. It is observed that after the application of the flow modifiers, there was $20 \%$ improvement in the RTD curves. The flow modifiers utilized in this study were dam, weir, baffles, and turbulence inhibitors. The turbulence inhibiter improved the fluid by terminating or minimizing the turbulence of the flow, which improves the inclusion removal rate [24-29]. The flow characteristic of the Millcon Steel PLC multistrand tundish utilized for continuous casting was investigated through CFD simulations and experimental testing. The primary focus was to improve the RTD curve, inclusion removal rate, and the quality of steel produced. The species transport model was utilized for simulating the tracer injection, and sodium chloride-colored dye was utilized in the physical scaled water model. It was observed from the RTD curves that the residence time was very lower at the center strand is comparable to others. It was concluded that the residence time could be improved by utilizing the flow modifier devices [14, 17], 28]. In a study, the fluid flow parameters of the tundish are investigated through a computational multiphase flow modeling developed for investigation, which is a volume of fluid (VOF). The tundish utilized in this study comprised the flow modifiers as flat and curved dams and weirs. The finite element analysis was carried out in ANSYS FLUENT software. It was concluded that the dam and weir with curved and flat shapes exhibit an improvement in the fluid flow characteristics [30-37].

\section{Materials and Methods}

\subsection{Constatations.}

The constatations (basic considerations) utilized in the modeling of the flow and inclusion removal of the multistrand tundish in this study are enlisted below: Effectuation of the generated slag layer over the top portion of the tundish is not taken into account in the analysis; The fluid utilized in the fluid flow is considered to be incompressible Newtonian fluid, and also the effect of the temperature concentration is disregarded; In actual the dispersion of the inclusions is slower than assumed in this analysis, and the formation of nonmetallic inclusions and their effect on flow is also disregarded; The inclusions dispersed in the fluid flow are considered rigid spheres, which are removed as soon as they float to the top section of the tundish.

\subsection{Regularizing equivalences.}

\subsubsection{Turbulency equations.}

The three-dimensional continuity and the Navier Stokes equation utilized are expressed below:

$$
\begin{gathered}
\frac{\partial}{\partial x_{i}}\left(\rho u_{i}\right)+\frac{\partial \rho}{\partial t}=0 \\
\frac{\partial\left(\rho u_{i}\right)}{\partial t}+\frac{\partial\left(\rho u_{i} u_{j}\right)}{\partial x_{i}}=-\frac{\partial P}{\partial x_{i}}+\frac{\partial}{\partial x_{j}}\left[\mu_{e f f}\left(\frac{\partial u_{j}}{\partial x_{i}}+\frac{\partial u_{i}}{\partial x_{j}}\right)\right]+\rho g
\end{gathered}
$$

Where the $u_{i}$ is the velocity of the fluid, $\rho$ is the density of the fluid, $u_{e f f}$ is the effective viscosity of the fluid, and $\mathrm{P}$ is the pressure. 
The turbulence in the fluid flow is expressed through the standard $\mathrm{k}-\varepsilon$ model in the following [36,37]:

$$
\begin{gathered}
\frac{\partial(\rho k)}{\partial t}+\frac{\partial}{\partial x_{i}}\left(\rho u_{i} k\right)=\frac{\partial}{\partial x_{j}}\left[\left(\mu+\frac{\mu_{t}}{\sigma_{\varepsilon}}\right) \frac{\partial k}{\partial x_{j}}\right]+G_{k}-\rho \varepsilon \\
\frac{\partial(\rho \varepsilon)}{\partial t}+\frac{\partial}{\partial x_{i}}\left(\rho u_{i} \varepsilon\right)=\frac{\partial}{\partial x_{j}}\left[\left(\mu+\frac{\mu_{t}}{\sigma_{\varepsilon}}\right) \frac{\partial \varepsilon}{\partial x_{j}}\right]+C_{1 \varepsilon} \frac{\varepsilon}{k} G_{k}-C_{2 \varepsilon \rho} \frac{\varepsilon^{2}}{k}
\end{gathered}
$$

Where the term $\mu_{t}$ is the turbulent viscosity and is calculated through the below equation:

$$
\mu_{t}=\rho C_{\mu} k^{2} / \varepsilon
$$

The constant values of the $C_{1 \varepsilon}, C_{2 \varepsilon}, C_{\mu}, \sigma_{k}$ and $\sigma_{\varepsilon}$ are $1.44,1.93,0.08,1.1$ and 1.4 respectively.

\subsubsection{Tracer dispersion.}

The diffusion behavior of the tracer is expressed through the conservation equation as follows:

$$
\frac{\partial\left(\rho C_{t}\right)}{\partial t}+\frac{\partial\left(\rho u_{i} C_{t}\right)}{\partial x_{i}}=\frac{\partial}{\partial x_{i}}\left(D_{e f f} \frac{\partial \rho C_{t}}{\partial x_{i}}\right)
$$

Where the $D_{e f f}$ is the effective diffusivity and $C_{t}$ is the concentration of the tracer.

\subsubsection{Motion of inclusions.}

The motion of the non-metallic inclusions in the fluid flow is expressed through the Lagrangian stochastic trajectory model, which is evaluated through solving BassetBoussinesqOseen (BBO) equation without considering the Basset force in the following [9]:

$$
\begin{aligned}
\left(1+\frac{\rho}{2 \rho_{p}}\right) \frac{d u_{p i}}{d t} & \\
& =\frac{f}{\tau_{p}}\left(u_{i}-u_{p i}\right)+\frac{3 \rho}{2 \rho_{p}} \frac{d u_{i}}{d t}+\left(1-\frac{\rho}{\rho_{p}}\right) g_{i} \\
& +1.53 \frac{\sqrt{\mu \rho}}{\rho_{p} R}\left(\frac{d u_{i}}{d y}\right)^{0.5}\left|u_{t}-u_{p t}\right|
\end{aligned}
$$

Where the terms on the right-hand side of the equation are inertia force, fluid resistance, pressure gradient force, gravitational force, and Saffman force, respectively. The terms $\tau_{p}=$ $\frac{2 \rho R_{p}^{2}}{9 \mu}$ and $R e_{p}=\frac{2 \rho R_{p}\left|u_{i}-u_{p i}\right|}{\mu}$ are the relaxation time and Reynolds number of inclusions respectively. The term $f$ is given by $f=C_{m}\left(1+0.15 R e_{p}^{0.687}\right)$. The terms $u_{i}$ and $u_{p i}$ are the tangential wall velocities of the steel and inclusions. The $\mathrm{R}$ is the radius of the inclusions. And also, the displacement of the inclusion is given by:

$$
x_{p i}=\int u_{p i} d t
$$

To simulate the turbulent fluctuations in motion of inclusions, the random walk model [36] has been deployed, and the continuous phase velocity is expressed as:

$$
u_{i}=\bar{u}_{\imath}+\xi \sqrt{2 k / 3}
$$

Where $\bar{u}_{\imath}$ is the time-averaged velocity, $\xi$ is the random number that obeys Gaussdistribution (which is ranged from zero to one), and $\mathrm{k}$ is the turbulent kinetic energy. 
There is a probability of adherence of the inclusions on the inner refractories of the tundish while flowing; the absorption stability of the tundish refractory depends on the Van der Waals force, shear force $\left(\tau_{w}\right)$, inclusion size and surface roughness, and many more. So, the inclusion absorption probability is given by:

$$
P_{a} \approx \exp \left(-\frac{0.287 \tau_{w}}{\tau_{\text {critical }}}\right)\left\{\frac{\leq \xi, \text { rebounding }}{>\xi, \text { adhesion }}\right.
$$

Where the $\tau_{\text {critical }}$ is the critical fluid shear force and is obtained by:

$$
\left(\frac{A R}{6 h^{2}}-6.46 \rho^{0.5} \mu^{-1} \tau_{\text {critical }}^{1.5} R^{3}\right) \frac{R \Delta}{R+\Delta}=43.92 \tau_{\text {critical }} R^{3}
$$

Where $A=2.3 \times 10^{-20} \mathrm{~J}$ is the Hamaker number [38]; it is the parameter that reflects the absorption strength of particles and plates. And $h=4 \mathrm{~nm}$, which is the stable spacing of Van der Waals force [39-47]. The $\mathrm{R}$ is the radius of inclusions, and for simplifying the simulation, the wall roughness $\Delta$ is assumed to be equal to the $\mathrm{R}$, through which optimum absorption effect can be achieved [44].

\subsection{Analytical analysis of RTD curves.}

\subsubsection{Mean residence time calculation.}

The evaluation of the residence time is the most critical study of the flow field parameters of the multistrand tundish, and the residence tie distribution (RTD) curves analyses also clarify the turbulence indices concerning the flow control devices application[19, 48-53].

The term $T_{a}$ stands for the average residence time of each strand and is calculated through:

$$
T_{a}=\frac{\sum t_{i} c_{i} \Delta t_{i}}{\sum c_{i} \Delta t_{i}}
$$

And the term $\overline{T_{a}}$ stands for the total average residence time of an $\mathrm{N}$-strand tundish, which is calculated through:

$$
\overline{T_{a}}=\frac{\sum_{i} \sum_{j} t_{i} c_{i} \Delta t_{i}}{\sum_{i} \sum_{j} c_{i} \Delta t_{i}}
$$

Where the term $\Delta t_{i}$ is a time interval, $t_{i}$ is sampling time and $c_{i}$ is a concentration of KCL resolution at $t_{i}$.

\subsubsection{Flow model calculation.}

The molten metal flow through the tundish comprises three types of zone formation: dead zone, plug zone, and well-mixed zone. Among these zones, the dead zone is extremely unwell-being to the tundish, which affects the tundish with respect to reduction in a working capacity. The well-mixed zone is beneficial for the temperature distribution in the tundish but not good for inclusion removal efficiency[20, 51, 52]. These zones' behavior and formation pattern are analyzed through analyzing the RTD curves, and in this study, an analysis method developed by a researcher [2] is utilized. For the purpose of briefing the deviation of real flow pattern with ideal plug flow, a variance is utilized, which is given by:

$$
\sigma_{i}^{2}=\int_{0}^{\infty}\left(t_{j}-\bar{t}_{j}\right)^{2} C_{i}\left(t_{j}\right) d t=\int_{0}^{\infty}\left(\theta_{j}-1\right)^{2} C_{i}\left(\theta_{j}\right) d \theta
$$




$$
\begin{gathered}
\sigma_{i}^{2}=\int_{0}^{\infty} \theta_{j}^{2} C_{i}\left(\theta_{j}\right) d \theta-1 \\
\sigma^{2}=\sum_{i=1}^{n} \sigma_{i}^{2}
\end{gathered}
$$

Where the term $\sigma^{2}$ ranges from 0 to 1 , and the full plug flow is represented through 0 value, and well-mixed flow is represented through 1 value. But when the back mixing area rises, the RTD becomes flat, and the same is followed by the $\sigma^{2}$.

The value of the residence time of dead zone $\left(V_{d}\right)$ can be evaluated through doubling the average residence time of the tundish through:

$$
\frac{V_{d i}}{V}=\int_{2 T_{a}}^{\infty} C_{i} d t, \quad \frac{V_{d}}{V}=\sum_{i=1}^{N} \frac{V_{d i}}{V}
$$

Further, the volume fraction of the well-mixed zone $\left(V_{m}\right)$ is evaluated through:

$$
\frac{V_{m i}}{V}=\sigma^{2}-\frac{V_{d i}}{V}-\frac{V_{m i}}{V}, \frac{V_{p}}{V}=\sum_{i=1}^{N} \frac{V_{p i}}{V}
$$

Further, the volume fraction of the plug zone $\left(V_{p}\right)$ is evaluated through:

$$
\frac{V_{p i}}{V}=\frac{1}{N}-\frac{V_{d i}}{V}-\frac{V_{m i}}{V}, \frac{V_{p}}{V}=\sum_{i=1}^{N} \frac{V_{p i}}{V}
$$

Where the term $V_{d i}$ stands for the volume fraction of dead zone at the ith strand, $V_{m i}$ stands for the volume fraction of well-mixed zone at the ith strand, $V_{p i}$ stands for the volume fraction of the plug zone at the ith strand, and V stands for the working volume of the tundish.

\subsubsection{Perspicacity of flow consistency in strands.}

To maintain proper consistency of the flow through all the strands in the multistrand tundish, the entire mean, standard deviation of the tracer concentration at each strand is required to be calculated, which is calculated through:

$$
\overline{S_{N}}=\frac{1}{Z} \sum_{j=1}^{Z} \sqrt{\sum_{i=1}^{N}\left[\left(C_{i}\left(\theta_{j}\right)-\frac{\bar{C}\left(\theta_{j}\right)^{2}}{N-1}\right]\right.},(i=1 \sim N, j=1 \sim Z)
$$

The lower the value of $\overline{S_{N}}$ the better the consistency of flow among the strands.

\subsection{Computational consideration.}

The fluid flow and inclusion removal analysis have been performed ion the multistrand tundish in this study, and the boundary constraints applied to the simulations and calculations are as follows: The velocity inlet is the type of inlet constraint applied, which comprises the velocity as $1 \mathrm{~m} / \mathrm{s}$, turbulence kinetic energy $(k)$ is $k=0.01 u_{\text {inlet }}^{2}$ and turbulence eddy dissipation $(\varepsilon)$ is $\varepsilon=2 k^{1.5} / d_{\text {inlet }}$; The speed of the casting process is kept constant throughout the casting, and outlet values are also set for a constant outlet; The variables at the symmetry plane comprise the horizontal gradients, which are also set none; In the case of the fee surface, the adiabatic constraint is applied, and the normative derivatives are set at zero; The walls of 
the tundish comprise the application of no-slip wall boundary constraint and treatment as standard wall function with normal gradients as none.

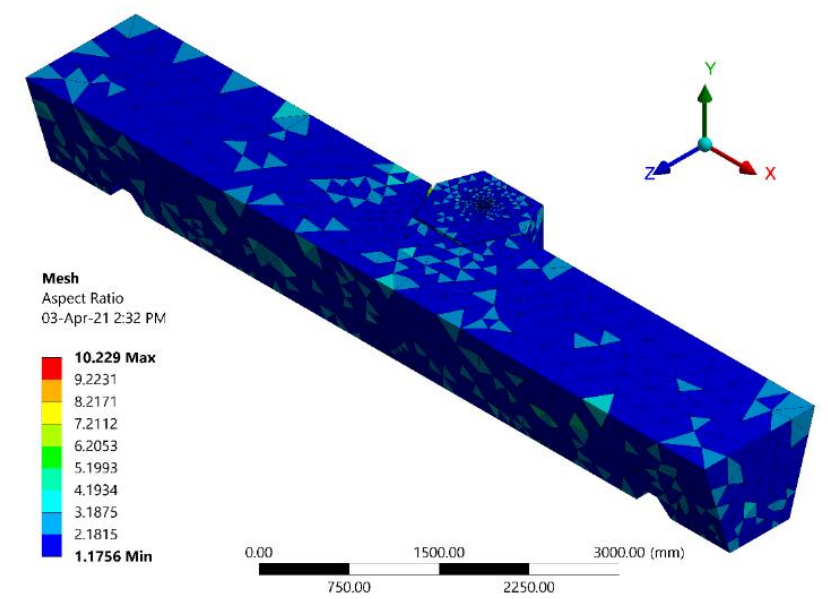

Figure 2. Tundish mesh model concerning aspect ratio.

Table 1. Tundish parameters and their values with units.

\begin{tabular}{c|c|c} 
Parameters & Value & Units \\
\hline Tundish working capacity & 360 & $\ell$ \\
\hline Cross-section of bloom & $56 \times 75$ & $\mathrm{~mm}^{2}$ \\
\hline Casting speed & 0.73 & $\mathrm{~m} / \mathrm{min}$ \\
\hline Molten metal level & 160 & $\mathrm{~mm}$ \\
\hline The inner diameter of the shroud & 85 & $\mathrm{~mm}$ \\
\hline Submergence depth of shroud & 60 & $\mathrm{~mm}$ \\
\hline Velocity of outlets & 0.669 & $\mathrm{~m} / \mathrm{s}$ \\
\hline Heat flux density & Free surface: 16.0 & $\mathrm{~kW} / \mathrm{m}^{2}$ \\
& Vertical sidewalls: 3.5 & \multirow{3}{*}{} \\
\cline { 2 - 2 } & Horizontal sidewalls: 4.0 & \multirow{3}{*}{} \\
\cline { 2 - 3 } & Bottom wall: 1.5 &
\end{tabular}

The analytical models are solved by utilizing the ANSYS FLUENT software commercial package. The mesh model concerning aspect ratio is shown in Fig. 2., which comprises application default mesh with tetrahedron elements. The default meshing was effective in managing the computational time and still maintaining the accuracy of the results. The parameters of the tundish compiled in the study are tabulated in Table. 1.

\section{Results and Discussion}

\subsection{Research proposition.}

The flow control devices critically affect the fluid flow in the tundish and its inclusion removal; in this study, they are baffles and turbulence inhibitors (TIs) [54-61]. To optimize the fluid flow, four different baffles are developed in this study, along with the original one shown in Fig. 1. For reducing the turbulence and inclusion, entrapment turbulence inhibiter is also developed in this study. The effect of this flow control device comprising the four baffles and two TIs on the fluid flow parameters and inclusion removal rate has been investigated in this study. The 3D model with dimensions of the four baffles and two TIs is shown in Fig. 3. The two TIs are named A and B types, and the four baffles are named V1, V1, V3, and V4, respectively. The tundish with each baffle type and TI is named as TV0 to TV8; this is tabulated in Table 2. 


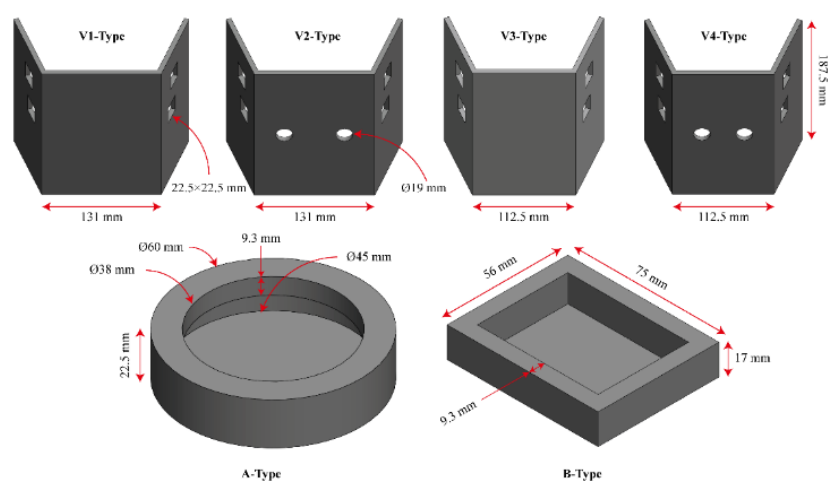

Figure 3. Dimensions of the four different baffles and two turbulence inhibitors (TIs).

Table 2. Types of tundish version with respect to TIs and baffles.

\begin{tabular}{l|c|c} 
Tundish versions & Turbulence inhibiter & Baffle \\
\hline TV0 & A-Type & Original \\
\hline TV1 & A-Type & V1-Type \\
\hline TV2 & A-Type & V2-Type \\
\hline TV3 & A-Type & V3-Type \\
\hline TV4 & A-Type & V4-Type \\
\hline TV5 & B-Type & V1-Type \\
\hline TV6 & B-Type & V2-Type \\
\hline TV7 & B-Type & V3-Type \\
\hline TV8 & B-Type & V4-Type
\end{tabular}

\subsection{Substantiation of the model.}

The validation of the simulation is done through a scaled water model experimental analysis, where the scale is 1:3. The correlation between the actual liquid metal and water model outcomes is expressed through the Froude numbers $\left(\mathrm{F}_{\mathrm{r}}\right)$, which is given below:

$$
F_{r p}=F_{r m}, \frac{V_{p}^{2}}{g L_{p}}=\frac{V_{m}^{2}}{g L_{m}}
$$

Where the terms $F_{r p}$ and $F_{r m}$ are Froude numbers, the terms $V_{p}$ and $V_{m}$ are velocities and the terms $L_{p}$ and $L_{m}$ are the characteristics lengths concerning actual and water model tundish. The scale factor between the actual and water model tundish is $\gamma=\frac{1}{3}$. The relationship of the flowrate, velocity and residence time of the actual and water model tundish is given by $\mathrm{Q}_{\mathrm{m}}=\gamma^{2.5} \mathrm{Q}_{\mathrm{p}}, \mathrm{V}_{\mathrm{m}}=\gamma^{0.5} \mathrm{~V}_{\mathrm{p}}$ and $\mathrm{t}_{\mathrm{m}}=\gamma^{0.5} \mathrm{t}_{\mathrm{p}}$ respectively.

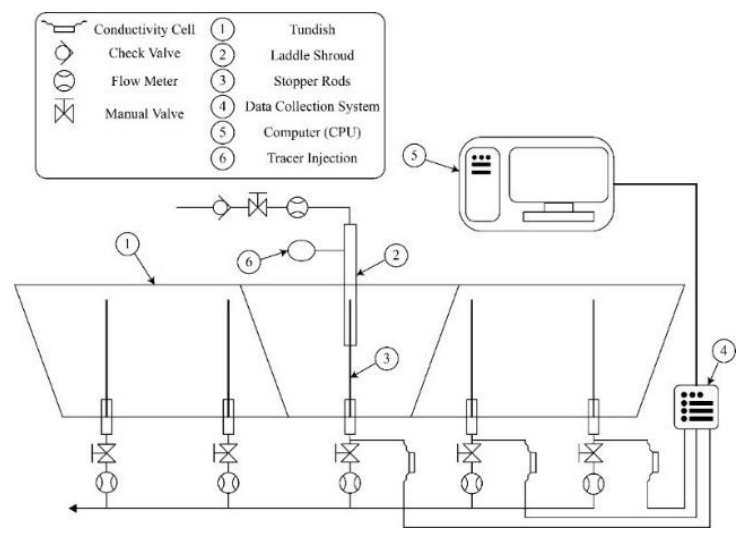

Figure 4. Schematic representation of the water model of tundish (experimental setup). 


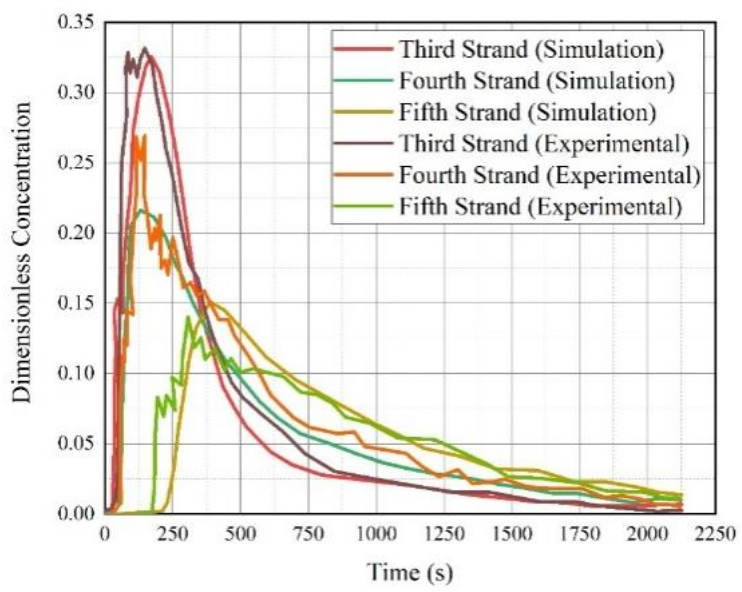

Figure 5. Simulation and experimental residence time distribution curves for tundish version TV0.
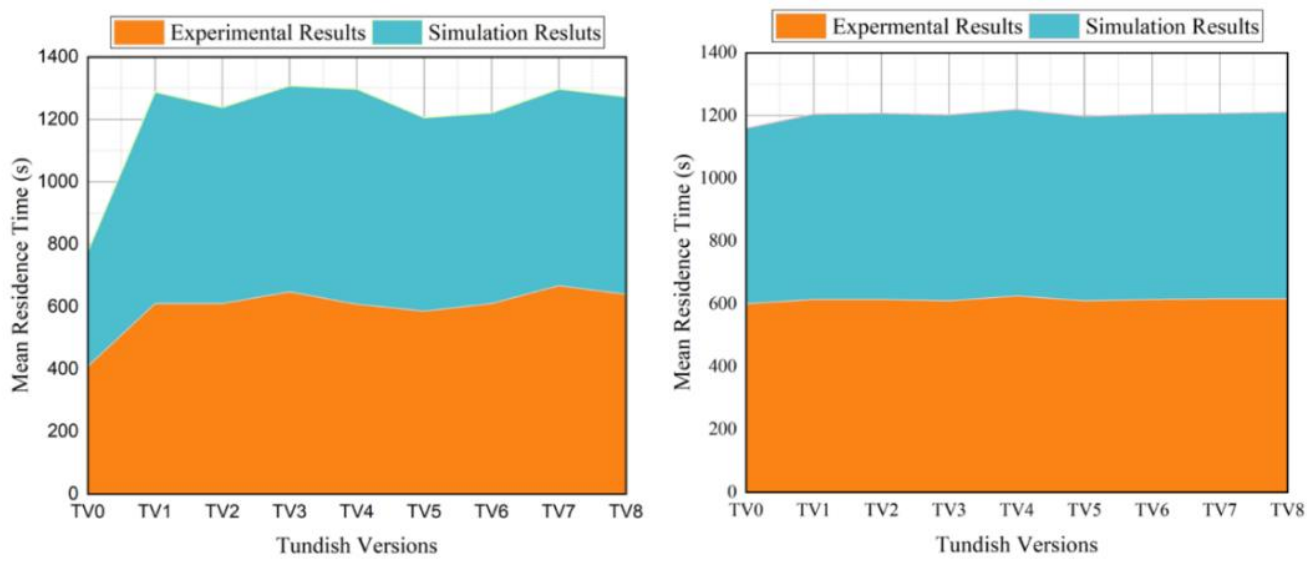

Figure 6. Simulation and experimental residence time distribution curves for (a) the third strand and (b) tundish version TV0.

The tracer in the water model experiment is chosen as the $20 \%$ sodium chloride (KCI) solution along with blue dye color. The tracer is injected from the inlet of the tundish (ladle shroud) for the time duration of four minutes after confirming the stability of the flow. The flow distribution is recorded through the camera, and the conductivity variation at the outlet is sensed by utilizing the electrodes. The conductivity variations are observed through conductivity cell, and scaled-up converted into dimensionless concentration and noted through the computer. The graph is prepared concerning dimensionless concentration and dimensionless time, which are the residence time distribution curves. The peak time, response time, mean residence time, volume ratio of the dead zone, plug zone, and the well-mixed zone is evaluated through these RTD curves. The residence time distribution curves at the third, fourth and fifth strands are shown in Fig. 5. and the water model experimental setup schematic diagram is shown in Fig.4.After observing Fig. 6, there is good agreement between the simulation and experimental evaluated RTD curves for the third strand and whole tundish with respect to the flow consistency. The error percentage between experimental and simulation mean residence time for different tundish versions is tabulated in Table 3.

Table 3. Error percentage between experimental and simulation mean residence time for different tundish

\begin{tabular}{l|c|c|c}
$\begin{array}{c}\text { Tundish } \\
\text { version }\end{array}$ & $\begin{array}{c}\text { Experimental mean } \\
\text { residence time (s) }\end{array}$ & $\begin{array}{c}\text { Simulation mean } \\
\text { residence time (s) }\end{array}$ & Errors (\%) \\
\hline TV0 & 605 & 565 & 6.61 \\
\hline TV1 & 620 & 595 & 4.03 \\
\hline TV2 & 615 & 592 & 3.73
\end{tabular}




\begin{tabular}{l|c|c|c}
$\begin{array}{l}\text { Tundish } \\
\text { version }\end{array}$ & $\begin{array}{c}\text { Experimental mean } \\
\text { residence time (s) }\end{array}$ & $\begin{array}{c}\text { Simulation mean } \\
\text { residence time (s) }\end{array}$ & Errors (\%) \\
\hline TV3 & 614 & 593 & 3.42 \\
\hline TV4 & 625 & 597 & 4.48 \\
\hline TV5 & 611 & 593 & 2.94 \\
\hline TV6 & 617 & 595 & 3.56 \\
\hline TV7 & 619 & 596 & 3.71 \\
\hline TV8 & 622 & 596 & 4.18
\end{tabular}

\subsection{Flow region analysis.}

Fig. 7. shows the particle path-lines and turbulence path-lines of the tundish version TV0, where it is the observer that the through the $3^{\text {rd }}$ stand is strong as compared to the other strands. From the velocity path-lines, it is observed that the velocity of the liquid metal flow is higher at the $3^{\text {rd }}$ strand as comparable to other strands. It is observed that the liquid metal enters the tundish and collides on the turbulence inhibiter and starts to roll out of the baffle and gradually flow to the $3^{\text {rd }}$ strand. The short circuit of the fluid flow at the $3^{\text {rd }}$ strand can observe. After that, the liquid metal flow towards the other strands with lower velocity. The reduction in the velocity during flowing to the end strands causes the dead zones. This weak flow velocity causes the formation of dead zones. The fluid flow in the TV0 is totally in a scattered form which reduces the possibility of the formation of plug flow. This causes the rise in the peak and response time at the other strands.

The design of the baffle in the tundish version TV0 comprises adverse effects to fluid flow, as the provision of the hole in the front section causes the short circuit of fluid flow at $3^{\text {rd }}$ strand and formation of dead zones at the $1^{\text {st }}$ and $5^{\text {th }}$ strands. The more holes on the baffles provide an excessive and uneven flow of the liquid metal, which must be optimized in the case of five strand tundish. In this study, four different types of baffles are designed applied to optimize the flow through the tundish to achieve the consistency of flow at all strands. The Fig. 8 to Fig. 15. shows the particle path-lines and turbulence path-lines of the tundish version TV1 to TV8, respectively.

To reduce the short circuit of fluid flow at 3rd strand and volume of dead zones, the four baffles are designed, and for reducing the turbulence, two types of TIs are also designed. The change in the baffle structure gradually changes the flow pattern of the liquid metal, which can be seen in Fig. 8. The liquid metal starts to flow from the upper section, and there is a reduction of the short circuit of the flow at the 3rd strand. There is an increase in the flow volume of liquid metal on the other sides of the tundish. The elimination of the larger holes in the center of the baffle results enhances the fluid flow in the tundish. As the flow prolongs at the 3rd strand, it is observed there is a decrease in the peak and response time at the 3rd strand. The minimization of the short circuit of fluid flow also results in a better inclusion removal rate. The impact of the fluid flow of liquid metal on the walls of the tundish can be reduced by designing the baffles correctly. There are also two types of TIs in the tundish, with primary focusing on the reduction of the impact effect and lowering the turbulence of the liquid metal at the entrance. The TIs structure has a higher effect on the flow behavior in the impact zone than the baffles. The utilization of the V2-type of TI causes higher rebounding and mixing of upward and downward flow, which causes an increase in turbulent kinetic energy and can also cause slag entrapment. The V1-type of the TI cause lower velocity fluid flow after impact, which minimizes the occurrence of slag entrapment and increases in turbulent kinetic energy. 


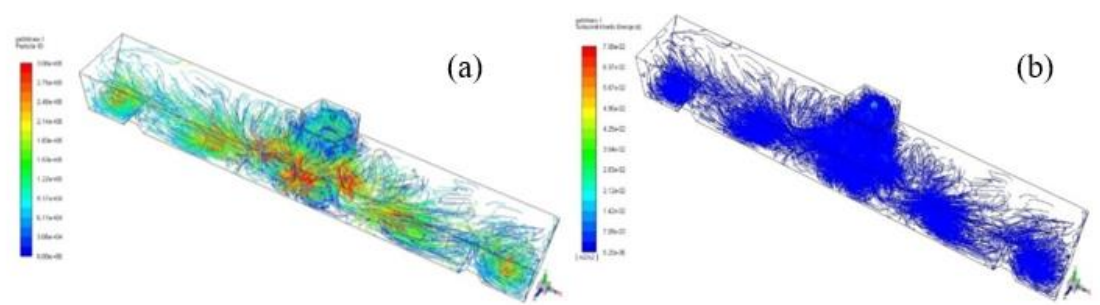

Figure 7. Tundish version TV0 (a) particle path-lines and (b) turbulence path-lines.

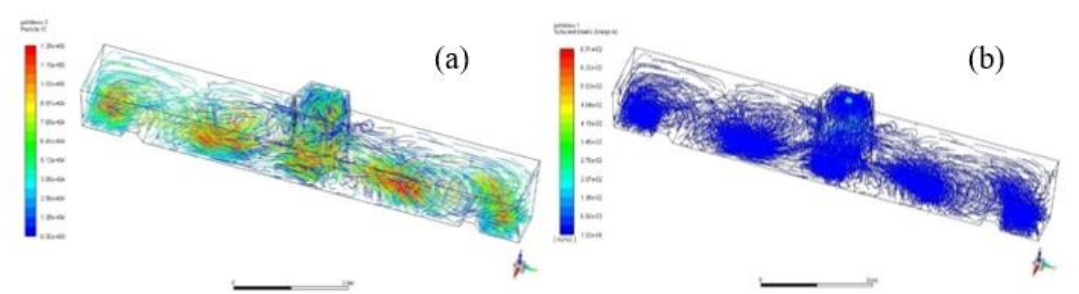

Figure 8. Tundish version TV1 (a) particle path-lines and (b) turbulence path-lines

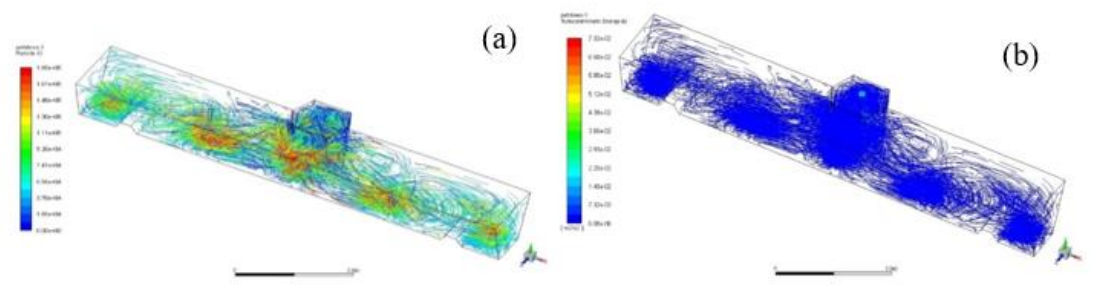

Figure 9. Tundish version TV2 (a) particle path-lines and (b) turbulence path-lines.

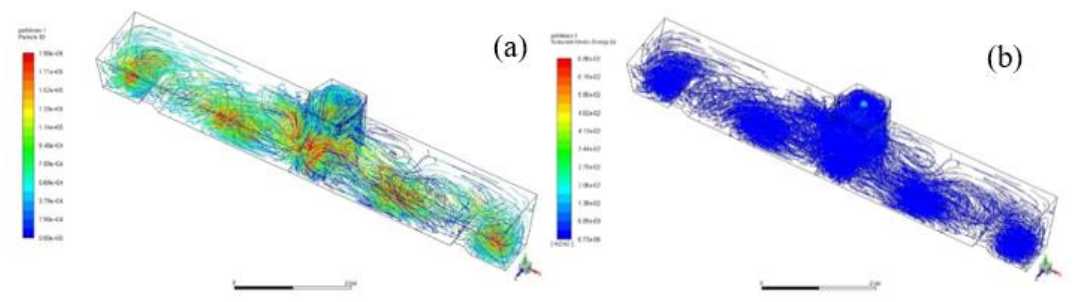

Figure 10. Tundish version TV3 (a) particle path-lines and (b) turbulence path-lines.

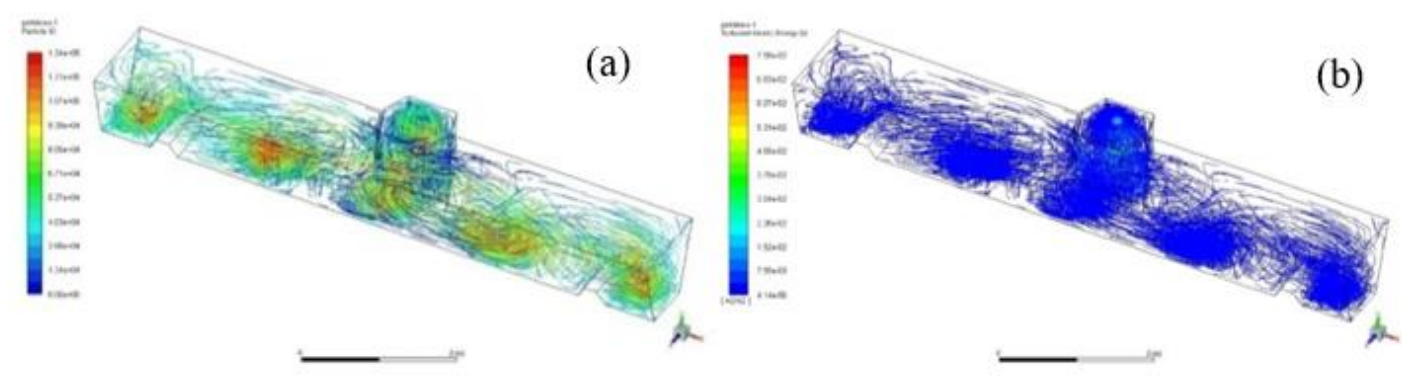

Figure 11. Tundish version TV4 (a) particle path-lines and (b) turbulence path-lines.
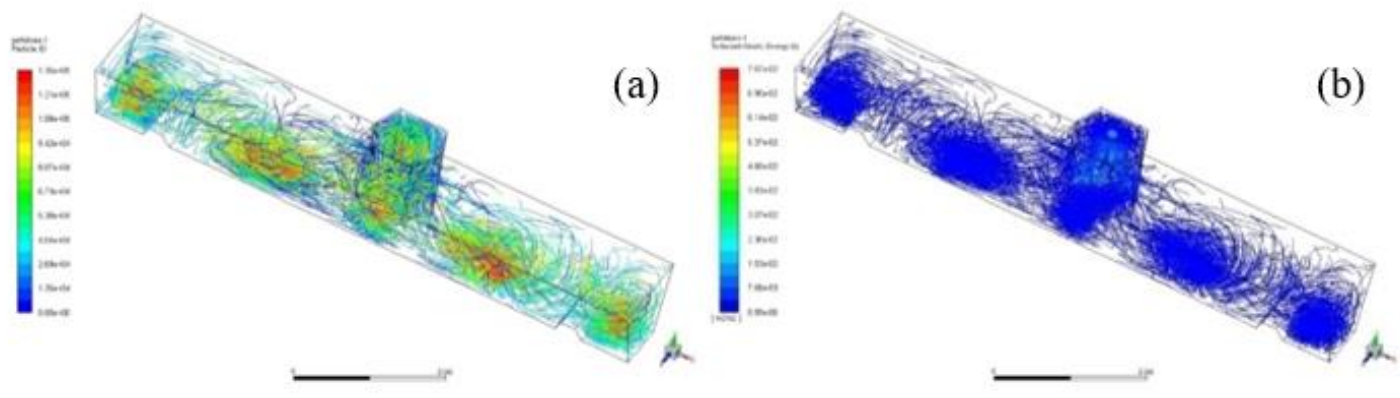
Figure 12.Tundish version TV5 (a) particle path-lines and (b) turbulence path-lines.

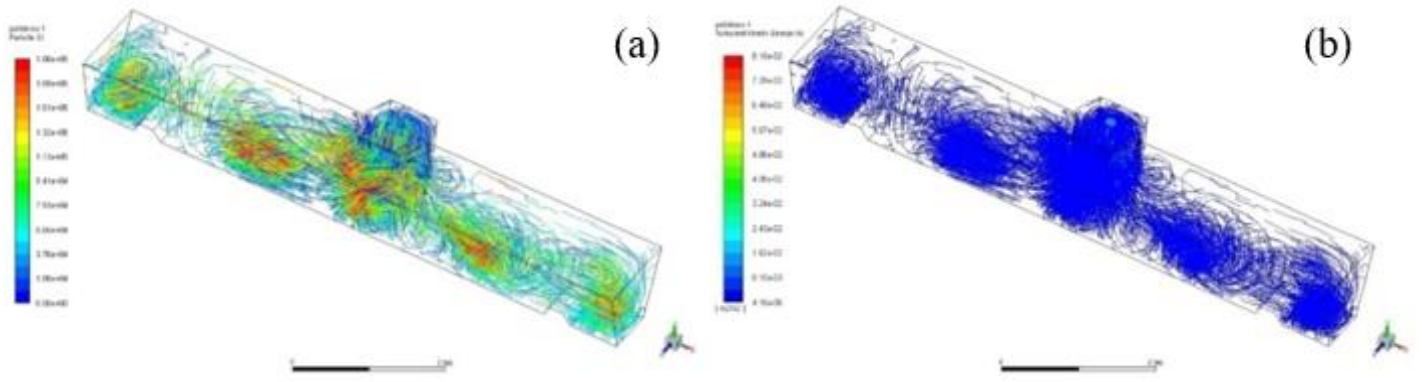

Figure 13.Tundish version TV6 (a) particle path-lines and (b) turbulence path-lines.
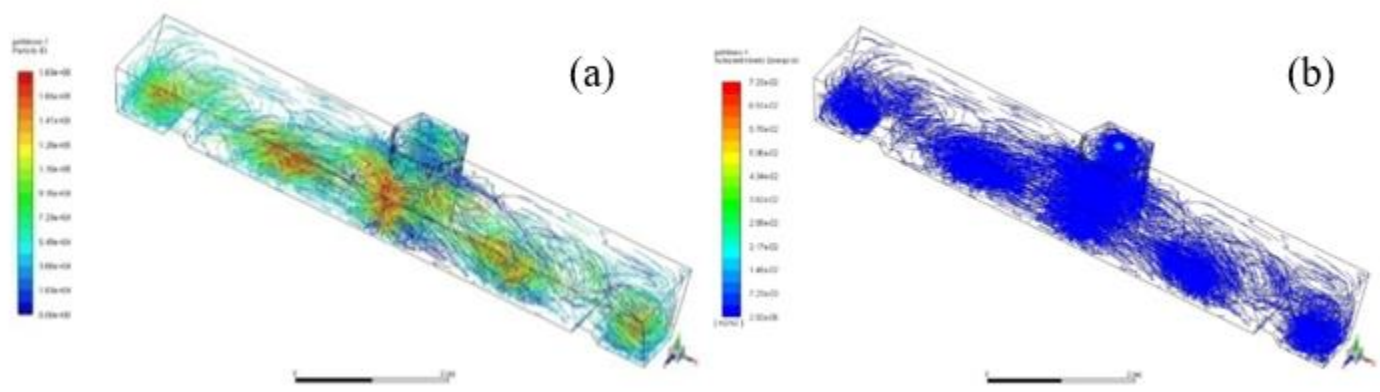

Figure 14. Tundish version TV7 (a) particle path-lines and (b) turbulence path-lines

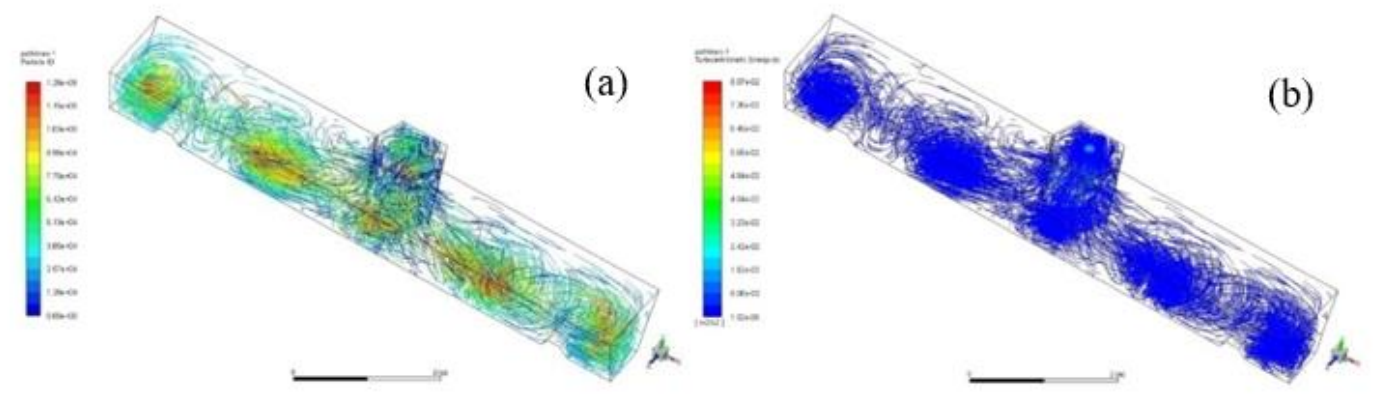

Figure 15. Tundish version TV8 (a) particle path-lines and (b) turbulence path-lines

\subsection{RTD curves analysis.}

The process of improving the fluid flow behavior in any odd multistrand tundish comprises the elimination of short-circuiting of the flow, sustaining the response and residence time, increasing the volume of plug zones, and reducing the dead zone formation [55]. The RTD curves for all the tundish versions are shown in Fig. 16. The values of the peak time, response time, residence time, volume ratios of plug zone, dead zone, and well-mixed zone, along with the mean, standard deviation of tracer concentration, are tabulated in Table. 4 . The response and peak time obtained for the tundish version TV0 are $190 \mathrm{~s}$ and $250 \mathrm{~s}$ for the 1st strand, and the mean, the standard deviation of the tracer concentration is 0.0227 , which is observed to be higher as compared to other tundish versions. The deviation in the residence time results in trouble in the inclusion removal process. The higher mean, standard deviation of tracer concentration results in higher inconsistency in the flow through the strands. The consistency directly results in the casting efficiency and quality of the casted product. It is observed in the other tundish version that the residence time is increased, which minimizes the possibility of the short-circuiting of the fluid flow, and this is also beneficial in the inclusion 
removal process. The increase in the volume percentage of the plug is observed along with a decrease in dead zone volume in the other tundish versions than TV0. These results show that there is improvement in the fluid flow parameters. The results found in the tundish versions TV1 to TV8 are similar, comprising higher peak and residence time at the 1st and 5th strand as comparable to the 3rd strand. The baffle version V1 and V3 types have proper fluid flow parameters; this presents that the tundish versions TV1, TV3, TV5, and TV7 are more effectively distributed. Among all the tundish versions, the TV8 is the optimum configuration for comparing the response and peak time and volume ratios of the plug zone, dead zone, and well-mixed zones.

\subsection{Inclusion removal analysis.}

\subsubsection{Inclusion size impression.}

The spherical inclusions are injected in the stream of the liquid metal at the inlet with different diameters, which are $10 \mu \mathrm{m}, 20 \mu \mathrm{m}, 40 \mu \mathrm{m}, 60 \mu \mathrm{m}, 80 \mu \mathrm{m}$, and $100 \mu \mathrm{m}$. The model utilized for the motion of these inclusions is the Lagrangian stochastic trajectory model. The tracer injection in the tundish version TV0 concerning different inclusion sizes is shown in Fig. 17. The inclusion removal rate of different tundish versions concerning inclusion sizes is shown in Fig. 18. It is observed that as the inclusion size increases, the inclusion removal rate increases. The inclusion removal rate for $10 \mu \mathrm{m}$ inclusions is between 40 to $60 \%$, and it is also observed that it is 70 to $90 \%$ for the $100 \mu \mathrm{m}$ inclusions. It was discovered that the inclusion having sizes between 10 to $40 \mu \mathrm{m}$ comprises a lower removal rate, as they get to escape to mold with the flow due to their lower buoyancy. The inclusion with a larger size has higher buoyancy and also comprises a higher inclusion removal rate. The removal rate increase by $25 \%$ after the inclusion is greater than $60 \mu \mathrm{m}$, and finally, for the inclusion size of 100 microns, the removal rate is $95 \%$.
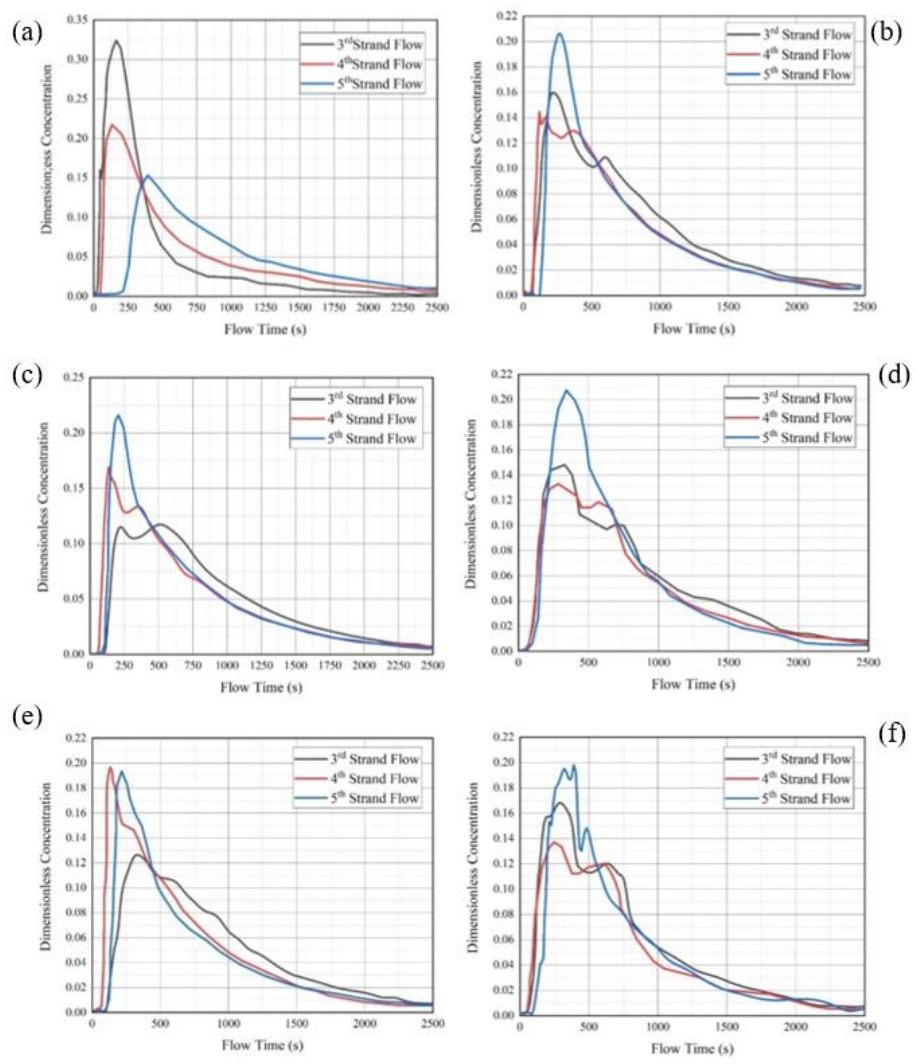

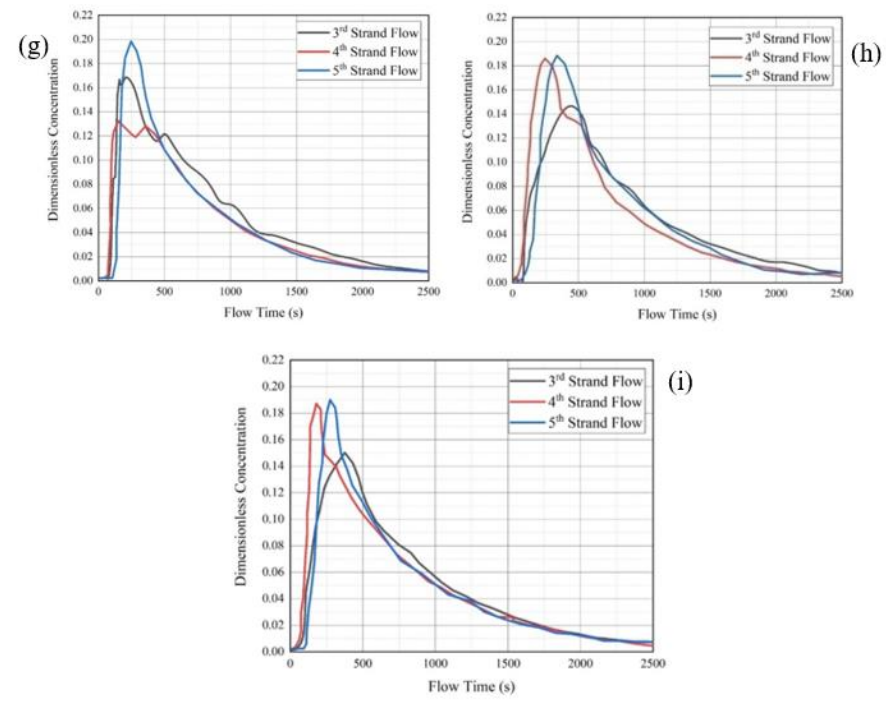

Figure 16. Residence time distribution curves for tundish version (a) TV0, (b) TV1, (c) TV2, (d) TV3, (e) TV4, (f) TV5, (g) TV6, (h) TV7 and (i) TV8.

Table 4. RTD analysis terms values for different tundish versions with respect to each strand.

\begin{tabular}{|c|c|c|c|c|c|c|c|c|c|c|}
\hline $\begin{array}{l}\text { Tundish } \\
\text { version }\end{array}$ & $\begin{array}{l}\text { No. of } \\
\text { strand }\end{array}$ & $\begin{array}{l}\mathbf{T}_{r} \\
(\mathbf{s})\end{array}$ & $\begin{array}{l}\mathbf{T}_{\mathbf{p}} \\
(\mathbf{s})\end{array}$ & $\begin{array}{l}\mathbf{T}_{\mathbf{a}} \\
(\mathbf{s})\end{array}$ & $\begin{array}{l}\overline{\mathbf{T}_{\mathbf{a}}} \\
(\mathbf{s})\end{array}$ & $\begin{array}{l}\mathbf{T}_{\mathrm{m}} \\
(\mathbf{s})\end{array}$ & $\begin{array}{r}\boldsymbol{V}_{\mathbf{p}} \\
(\%)\end{array}$ & $\begin{array}{r}\mathbf{V}_{\mathbf{d}} \\
(\%)\end{array}$ & $\begin{array}{l}\mathbf{V}_{\mathbf{m}} \\
(\%)\end{array}$ & $\overline{\mathbf{S}_{\mathrm{N}}}$ \\
\hline \multirow{5}{*}{ TV0 } & $1^{\text {st }}$ & 190 & 250 & 299 & \multirow{5}{*}{562} & \multirow{5}{*}{760} & \multirow{5}{*}{50} & \multirow{5}{*}{15} & \multirow{5}{*}{38} & \multirow{5}{*}{0.0227} \\
\hline & $2^{\text {nd }}$ & 30 & 134 & 340 & & & & & & \\
\hline & $3^{\text {rd }}$ & 22 & 163 & 368 & & & & & & \\
\hline & $4^{\text {th }}$ & 43 & 135 & 494 & & & & & & \\
\hline & $5^{\text {th }}$ & 200 & 390 & 729 & & & & & & \\
\hline \multirow{5}{*}{ TV1 } & $1^{\text {st }}$ & 44 & 216 & 555 & \multirow{5}{*}{595} & \multirow{5}{*}{762} & \multirow{5}{*}{54} & \multirow{5}{*}{14} & \multirow{5}{*}{34} & \multirow{5}{*}{0.0079} \\
\hline & $2^{\text {nd }}$ & 56 & 222 & 520 & & & & & & \\
\hline & $3^{\text {rd }}$ & 84 & 215 & 680 & & & & & & \\
\hline & $4^{\text {th }}$ & 47 & 143 & 578 & & & & & & \\
\hline & $5^{\text {th }}$ & 82 & 205 & 572 & & & & & & \\
\hline \multirow{5}{*}{ TV2 } & $1^{\text {st }}$ & 56 & 150 & 524 & \multirow{5}{*}{592} & \multirow{5}{*}{761} & \multirow{5}{*}{54} & \multirow{5}{*}{14} & \multirow{5}{*}{35} & \multirow{5}{*}{0.0050} \\
\hline & $2^{\text {nd }}$ & 58 & 210 & 555 & & & & & & \\
\hline & $3^{\text {rd }}$ & 68 & 214 & 627 & & & & & & \\
\hline & $4^{\text {th }}$ & 49 & 135 & 590 & & & & & & \\
\hline & $5^{\text {th }}$ & 87 & 196 & 578 & & & & & & \\
\hline \multirow{5}{*}{ TV3 } & $1^{\text {st }}$ & 86 & 245 & 560 & \multirow{5}{*}{593} & & & & & \\
\hline & $2^{\text {nd }}$ & 75 & 222 & 566 & & & & & & \\
\hline & $3^{\text {rd }}$ & 85 & 205 & 660 & & 762 & 55 & 14 & 33 & 0.0075 \\
\hline & $4^{\text {th }}$ & 49 & 139 & 578 & & & & & & \\
\hline & $5^{\text {th }}$ & 87 & 218 & 575 & & & & & & \\
\hline & $1^{\mathrm{st}}$ & 75 & 195 & 523 & & & & & & \\
\hline & $2^{\text {nd }}$ & 66 & 235 & 589 & & & & & & \\
\hline TV4 & $3^{\text {rd }}$ & 74 & 327 & 690 & 597 & 763 & 55 & 13 & 33 & 0.0078 \\
\hline & $4^{\text {th }}$ & 53 & 125 & 560 & & & & & & \\
\hline & $5^{\text {th }}$ & 96 & 200 & 620 & & & & & & \\
\hline & $1^{\text {st }}$ & 78 & 177 & 546 & & & & & & \\
\hline & $2^{\text {nd }}$ & 87 & 188 & 512 & & & & & & \\
\hline TV5 & $3^{\text {rd }}$ & 80 & 177 & 590 & 594 & 762 & 56 & 14 & 34 & 0.0065 \\
\hline & $4^{\text {th }}$ & 52 & 153 & 584 & & & & & & \\
\hline & $5^{\text {th }}$ & 95 & 214 & 610 & & & & & & \\
\hline & $1^{\mathrm{st}}$ & 98 & 245 & 565 & & & & & & \\
\hline & $2^{\text {nd }}$ & 89 & 233 & 545 & & & & & & \\
\hline TV6 & $3^{\text {rd }}$ & 70 & 209 & 610 & 595 & 764 & 55 & 13 & 33 & 0.0066 \\
\hline & $4^{\text {th }}$ & 52 & 244 & 594 & & & & & & \\
\hline & $5^{\text {th }}$ & 100 & 245 & 588 & & & & & & \\
\hline & $1^{\mathrm{st}}$ & 84 & 184 & 562 & & & & & & \\
\hline & $2^{\text {nd }}$ & 87 & 156 & 516 & & & & & & \\
\hline TV7 & $3^{\text {rd }}$ & 79 & 190 & 630 & 595 & 763 & 53 & 14 & 35 & 0.0078 \\
\hline & $4^{\text {th }}$ & 50 & 152 & 584 & & & & & & \\
\hline & $5^{\text {th }}$ & 103 & 258 & 590 & & & & & & \\
\hline TV8 & $1^{\text {st }}$ & 60 & 250 & 611 & 596 & 765 & 55 & 14 & 33 & 0.0060 \\
\hline
\end{tabular}




\begin{tabular}{|c|c|c|c|c|c|c|c|c|c|c|}
\hline $\begin{array}{l}\text { Tundish } \\
\text { version }\end{array}$ & $\begin{array}{l}\text { No. of } \\
\text { strand }\end{array}$ & $\begin{array}{l}\mathbf{T}_{\boldsymbol{r}} \\
(\mathbf{s})\end{array}$ & $\begin{array}{l}\mathbf{T}_{\mathbf{p}} \\
(\mathbf{s})\end{array}$ & $\begin{array}{l}\mathbf{T}_{\mathbf{a}} \\
(\mathbf{s})\end{array}$ & $\begin{array}{l}\overline{\mathbf{T}_{\mathbf{a}}} \\
(\mathbf{s})\end{array}$ & $\begin{array}{l}\mathbf{T}_{\mathbf{m}} \\
(\mathbf{s})\end{array}$ & $\begin{array}{r}\boldsymbol{V}_{\mathbf{p}} \\
(\%)\end{array}$ & $\begin{array}{r}\mathbf{V}_{\mathbf{d}} \\
(\%)\end{array}$ & $\begin{array}{l}\mathbf{V}_{\mathbf{m}} \\
(\%)\end{array}$ & $\overline{\mathbf{S}_{\mathrm{N}}}$ \\
\hline & $2^{\text {nd }}$ & 71 & 330 & 542 & & & & & & \\
\hline & $3^{\text {rd }}$ & 64 & 373 & 633 & & & & & & \\
\hline & $4^{\text {th }}$ & 54 & 123 & 572 & & & & & & \\
\hline & $5^{\text {th }}$ & 101 & 206 & 602 & & & & & & \\
\hline
\end{tabular}

3.5.2. Turbulence inhibiter (TI) impression.

The Fig. 19. shows the tracer injection with all inclusion sizes in different tundish versions. It is seen that the motion of the inclusion is concentrated at the $2^{\text {nd }}, 3^{\text {rd }}$ and $4^{\text {th }}$ strand of the tundish and rarely flows to the $1^{\text {st }}$ and $5^{\text {th }}$ strand of the tundish. After applying the TIs, the inclusion escaping at the $3^{\text {rd }}$ strand is decreased, and the consistency of the flow is achieved. This also forces the inclusion to flow upward for traveling to the other strands, which is beneficial in forming a slag layer over the top section. The ability of the inclusion having small sizes is relatively lower, and they flow with fluid, which causes it's difficult to enhance the removal rate. The inclusions with greater size (greater than $50 \mu \mathrm{m}$ ) compressibility to float on the top and also travel less, so the higher removal rate as slag layer can be obtained. The optimum inclusion removal rate is discovered to be of tundish version TV8, which comprises the increase in inclusion removal rate as comparable to TV0 concerning diameters $10,20,40$, 60,80 , and $100 \mu \mathrm{m}$ are $0.8,1.2,3.2,5.2,5.9$ and $8.1 \%$ respectively.

(a)

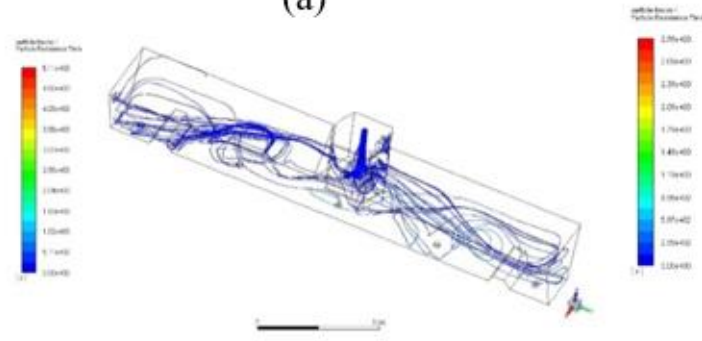

(c)
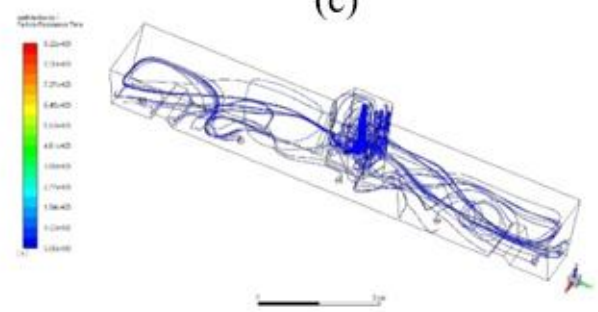

(e)
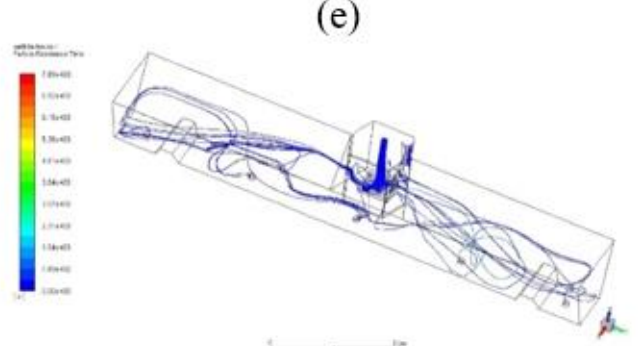
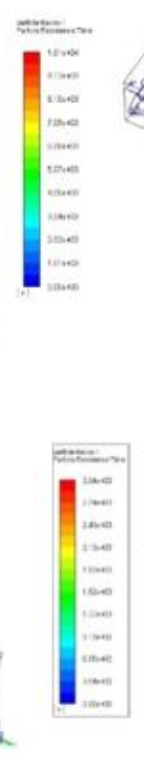

(b)

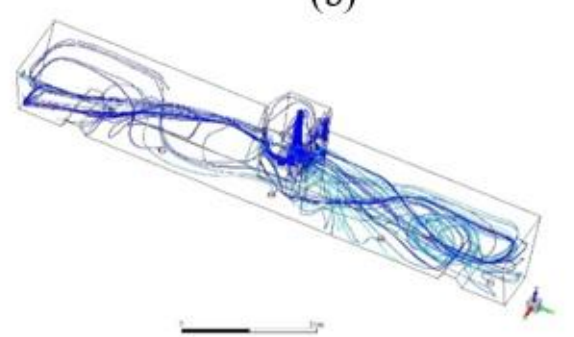

(d)

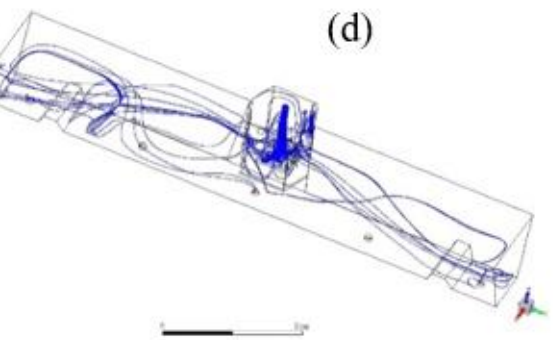

(f)

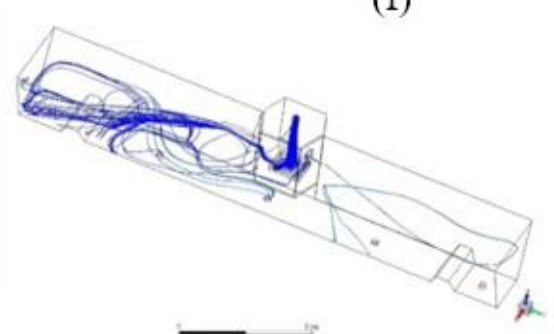

Figure 17.Tracer injection in the tundish version TV0 with respect to inclusion size (a) $10 \mu \mathrm{m}$, (b) $20 \mu \mathrm{m}$, (c) 40 $\mu \mathrm{m}$, (d) $60 \mu \mathrm{m}$, (e) $80 \mu \mathrm{m}$ and (f) $100 \mu \mathrm{m}$. 


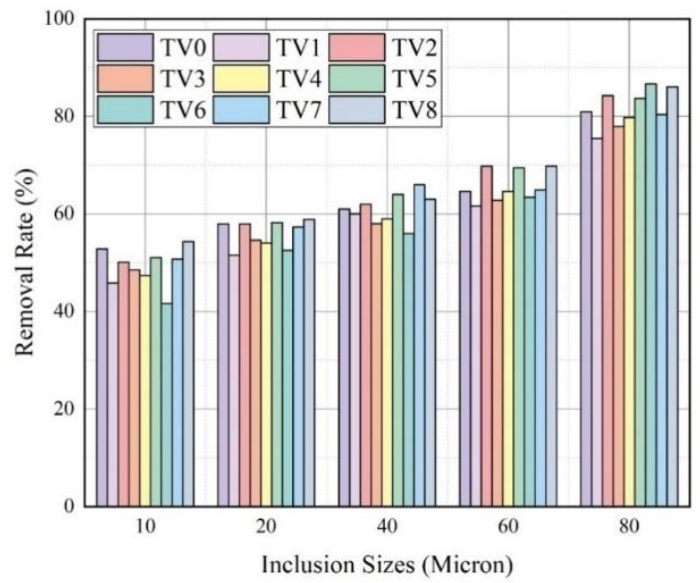

Figure 18. The inclusion removal rate of different tundish versions with respect to inclusion size (a).
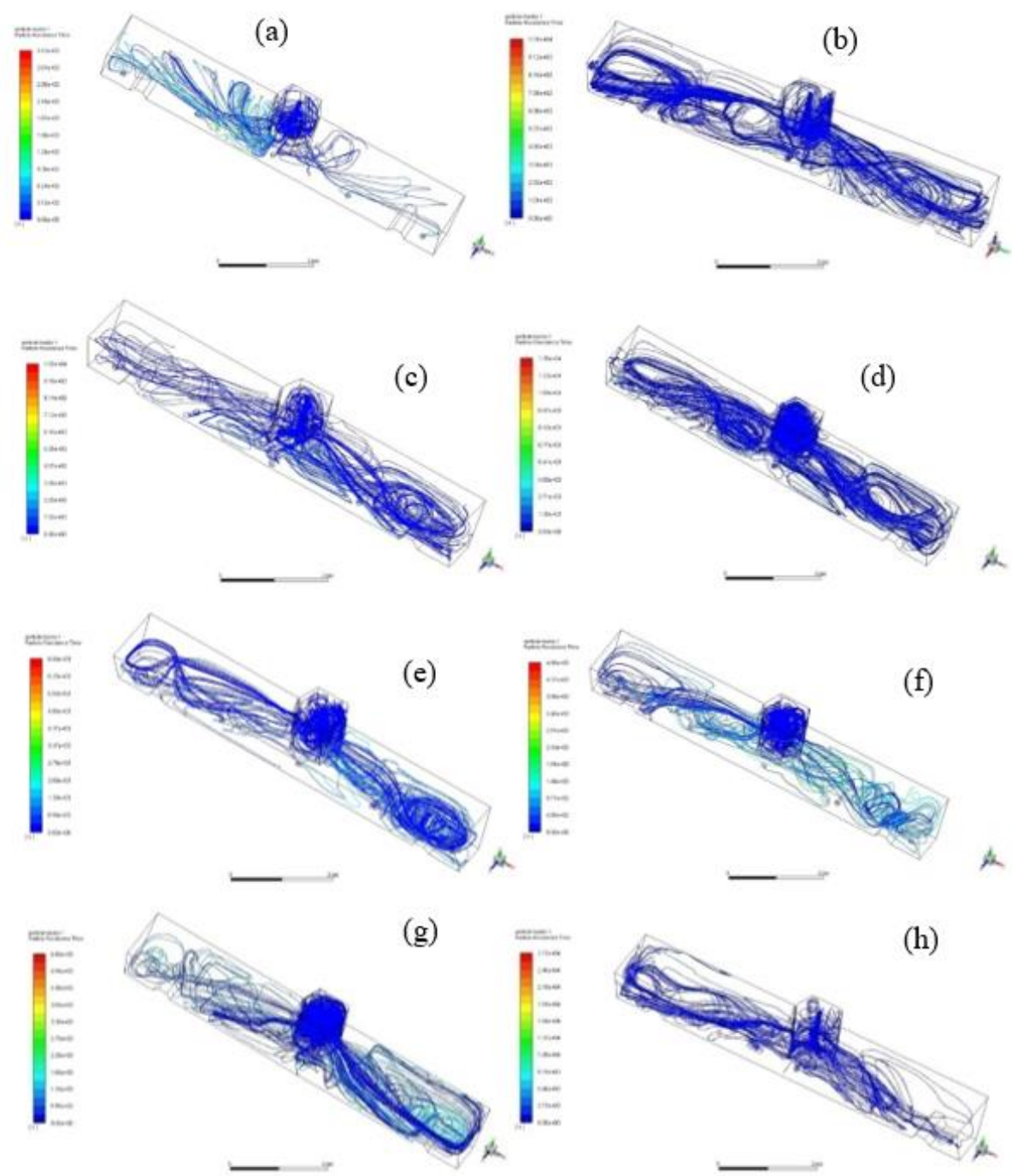

(h)

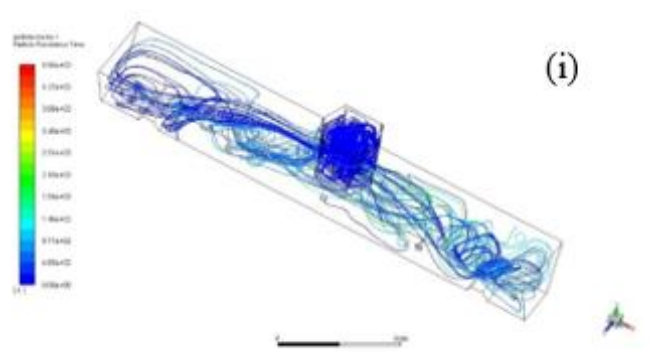

Figure 19.Tracer injection with all inclusion sizes in tundish version (a) TV0, (b) TV1, (c) TV2, (d) TV3, (e) TV4, (f) TV5, (g) TV6, (h) TV7 and (i) TV8. 
4. Conclusions

This study comprises the investigation of five strand tundish with four different baffles and two different TIs concerning the fluid flow pattern and motion of the inclusion in the fluid flow. The conclusions obtained from the results obtained from the simulation and experimental analysis are listed below:

The fluid flow analysis and RTD analysis results obtained through the simulation and experimental results have a higher error of $6.61 \%$, which is for tundish version TV0 and other errors are lower than $4.5 \%$. The application of the baffles with lower flow diversion holes on the center section comprises the benefits of enhancement of the plug zone and consistency among the strands, reduction in dead zone volume, sustaining peak and residence time, and elimination of the short circuit of fluid flow at $3^{\text {rd }}$ strand. The fluid flow velocity at the free surface is decreased due to the application of the A-type of TI in the tundish.

The optimum tundish version is TV8, which comprises residence time of $596 \mathrm{~s}$, increased volume of plug zone by $5 \%$, and decrease in a dead zone by $1 \%$ concerning TV0, and the mean standard deviation of the tracer concentration is 0.0060 .

\section{Funding}

This research received no external funding.

\section{Acknowledgments}

Jaywant N. Yadav gratefully thanks Dr. D. K. Rajak, Assistant Professor, Department of Mechanical Engineering, at Sandip Institute of Technology and Research Centre, Nashik, for going through the manuscript providing valuable comments and suggestions for improving the quality of this work.

\section{Conflicts of Interest}

The authors declare no conflict of interest.

\section{References}

1. Fang, Q.; Zhang, H.; Luo, R.; Liu, C.; Wang, Y.; Ni, H. Optimization of flow, heat transfer and inclusion removal behaviors in an odd multistrand bloom casting tundish. Journal of Materials Research and Technology 2020, 9, 347-363,https://doi.org/10.1016/j.jmrt.2019.10.064.

2. Pan, H.; Cheng, S. Mathematical model of flow characteristic in multistrand continuous casting tundishes. Acta Metallurgica Sinica (English Letters) 2009, 22, 297-307,https://doi.org/10.1016/S1006-7191(08)601027.

3. Sousa Rocha, J.R.d.; Souza, E.E.B.d.; Marcondes, F.; Castro, J.A.d. Modeling and computational simulation of fluid flow, heat transfer and inclusions trajectories in a tundish of a steel continuous casting machine. Journal of Materials Research and Technology 2019, 8, 42094220,https://doi.org/10.1016/j.jmrt.2019.07.029.

4. Zepeda-Diaz, F.A.; Garcia-Hernandez, S.; Barreto, J.d.J.; Gutierrez, E. Mathematical Modelling of the Effects of Transient Phenomena on Steel Cleanness during Tundish Transfer Practices. ISIJ International 2019, 59, 51-59,https://doi.org/10.2355/isijinternational.ISIJINT-2018-527.

5. Liu, S.-X.; Yang, X.-M.; Du, L.; Li, L.; Liu, C.-Z. Hydrodynamic and Mathematical Simulations of Flow Field and Temperature Profile in an Asymmetrical T-type Single-strand Continuous Casting Tundish. ISIJ International 2008, 48, 1712-1721, https://doi.org/10.2355/isijinternational.48.1712.

6. Merder, T. Modelling the influence of changing constructive parameters of multistrand tundish on steel flow and heat transfer. Ironmaking \& Steelmaking 2016, 43, 758768,https://doi.org/10.1080/03019233.2016.1209825. 
7. Qu, T.-P.; Liu, C.-J.; Jiang, M.-F.; Zu, L.-Y. Numerical Simulation for Effect of Inlet Cooling Rate on Fluid Flow and Temperature Distribution in Tundish. Journal of Iron and Steel Research International 2012, 19, 12-19,https://doi.org/10.1016/s1006-706x(12)60107-1.

8. Yadav, J.; Singh, N. Production of metal production in casting through tundish: A review.Gorteria Journal2020, 33, 355-376.

9. Crowe, C.T.; Schwarzkopf, J.D.; Sommerfeld, M.; Tsuji, Y. Multiphase Flows with Droplets and Particles, Second Edition. CRC Press2011,https://doi.org/10.1201/b11103.

10. Su, X.; Ji, Y.; Liu, J.; He, Y.; Shen, S.; Cui, H. Analysis on Residence Time Distribution Curve of Continuous Casting Tundish by Combined Model.Steel research international2018, 89, https://doi.org/10.1002/srin.201800085.

11. Tripathi, A.; Ajmani, S.K. Effect of Shape and Flow Control Devices on the Fluid Flow Characteristics in Three Different Industrial Six Strand Billet Caster Tundish. ISIJ International 2011, 51, 16471656,https://doi.org/10.2355/isijinternational.51.1647.

12. Mishra, R.; Mazumdar, D. Numerical Analysis of Turbulence Inhibitor Toward Inclusion Separation Efficiency in Tundish. Transactions of the Indian Institute of Metals 2019, 72, 889-898, https://doi.org/10.1007/s12666-018-1547-x.

13. Jin, Y.; Dong, X.; Yang, F.; Cheng, C.; Li, Y.; Wang, W. Removal Mechanism of Microscale Non-Metallic Inclusions in a Tundish with Multi-Hole-Double-Baffles. Metals 2018, 8,https://doi.org/10.3390/met8080611.

14. Sahai, Y. Tundish Technology for Casting Clean Steel: A Review. Metallurgical and Materials Transactions B 2016, 47, 2095-2106, https://doi.org/10.1007/s11663-016-0648-3.

15. Gardin, P.; Brunet, M.; Domgin, J.F.; Pericleous, K. An experimental and numerical CFD study of turbulence in a tundish container. Applied Mathematical Modelling 2002, 26, 323-336,https://doi.org/10.1016/S0307904X(01)00064-6.

16. Kumar, A.; Koria, S.C.; Mazumdar, D. An Assessment of Fluid Flow Modelling and Residence Time Distribution Phenomena in Steelmaking Tundish Systems. ISIJ International 2004, 44, 13341341,https://doi.org/10.2355/isijinternational.44.1334.

17. Mazumdar, D.; Guthrie, R.I.L. The Physical and Mathematical Modelling of Continuous Casting Tundish Systems. ISIJ International 1999, 39, 524-547,https://doi.org/10.2355/isijinternational.39.524.

18. Chen, C.; Ni, P.; Jonsson, L.T.I.; Tilliander, A.; Cheng, G.; Jönsson, P.G. A Model Study of Inclusions Deposition, Macroscopic Transport, and Dynamic Removal at Steel-Slag Interface for Different Tundish Designs. Metallurgical and Materials Transactions B 2016, 47, 1916-1932, https://doi.org/10.1007/s11663016-0637-6.

19. Alizadeh, M.; Edris, H.; Shafyei, A. Fluid Flow and Mixing in Non-Isothermal Water Model of Continuous Casting Tundish. Journal of Iron and Steel Research International 2008, 15, 7-13, https://doi.org/10.1016/S1006-706X(08)60022-9.

20. Raghavendra, K.; Sarkar, S.; Ajmani, S.K.; Denys, M.B.; Singh, M.K. Mathematical modelling of single and multistrand tundish for inclusion analysis. Applied Mathematical Modelling 2013, 37, 62846300,https://doi.org/10.1016/j.apm.2013.01.013.

21. Harnsihacacha, A.; Piyapaneekoon, A.; Kowitwarangkul, P. Physical water model and CFD studies of fluid flow in a single strand tundish. Materials Today: Proceedings 2018, 5, 9220-9228, https://doi.org/10.1016/j.matpr.2017.10.093.

22. Chattopadhyay, K.; Isac, M.; Guthrie, R.I.L. Physical and Mathematical Modelling of Steelmaking Tundish Operations: A Review of the Last Decade (1999\&ndash;2009). ISIJ International 2010, 50, 331-348, https://doi.org/10.2355/isijinternational.50.331.

23. Bul'ko, B.; Kijac, J. Optimization of tundish equipment.Acta Metallurgica Slovaca2010, 16, $76-83$.

24. Minin, I.V.; Minin, O.V. Computational Fluid Dynamics Technologies and Applications. 2011.

25. Kowitwarangkul, P.; Kamonrattanapisud, M.; Juntasaro, E. CFD Simulation of Molten Steel Flow with Isothermal Condition in the Continuous Casting Tundish. KMUTNB International Journal of Applied Science and Technology 2015, 1-7, https://doi.org/10.14416/j.ijast.2015.12.003.

26. Kowitwarangkul, P.; Harnsihacacha, A. Tracer Injection Simulations and RTD Analysis for the Flow in 3Strands Steelmaking Tundish. Key Engineering Materials 2017, 728, 72-77, https://doi.org/10.4028/www.scientific.net/KEM.728.72.

27. Shih, T.-H.; Liou, W.W.; Shabbir, A.; Yang, Z.; Zhu, J. A new k-€ eddy viscosity model for high reynolds number turbulent flows. Computers \& Fluids 1995, 24, 227-238,https://doi.org/10.1016/00457930(94)00032-T.

28. Harnsihacacha, A.; Piyapaneekoon, A.; Wattanaporn, C.; Kowitwarangkul, P. Flow prediction in the multistrand continuous casting tundish of Millcon Steel PLC. Materials Today: Proceedings 2018, 5, 92299237,https://doi.org/10.1016/j.matpr.2017.10.094.

29. Khan, M.F.; Hussain, A.; Usmani, A.Y.; Yadav, R.; Jafri, S.A.H. Multiphase Flow Modeling of Molten Steel and Slag Flow for Different Tundish Configurations. Materials Today: Proceedings 2018, 5, 2491524923,https://doi.org/10.1016/j.matpr.2018.10.291. 
30. He, Z.; Zhou, K.; Liu, S.; Xiong, W.; Li, B. Numerical Modeling of the Fluid Flow in Continuous Casting Tundish with Different Control Devices. Abstract and Applied Analysis 2013, 2013,https://doi.org/10.1155/2013/984894.

31. Thomas, B.; Bai, H.; Sivaramakrishnan, S.; Pratap, S. Detailed Simulation of Flow in Continuous Casting of Steel using K-E, LES, and PIV. International Symposium on Cutting Edge of Computer Simulation of Solidification and Processes 1999.

32. Thomas, B.G.; Yuan, Q.; Mahmood, S.; Liu, R.; Chaudhary, R. Transport and Entrapment of Particles in Steel Continuous Casting. Metallurgical and Materials Transactions B 2014, 45, 22-35, https://doi.org/10.1007/s11663-013-9916-7.

33. Bielnicki, M.; Jowsa, J.; Cwudziński, A. Multiphase Numerical Model of Molten Steel and Slag Behavior in the Continuous Casting Mould.Archives of Metallurgy and Materials2015, 60,https://doi.org/10.1515/amm-2015-0041.

34. Lopez, P.E.R.; Jalali, P.N.; Björkvall, J.; Sjöström, U.; Nilsson, C. Recent Developments of a Numerical Model for Continuous Casting of Steel: Model Theory, Setup and Comparison to Physical Modelling with Liquid Metal. ISIJ International 2014, 54, 342-350,https://doi.org/10.2355/isijinternational.54.342.

35. Machado-Lopez, M.M.; Ramos-Banderas, J.A.; Torres-Alonso, E.; Barreto, J.J.; Garcia-Hernandez, S. Multiphase modelling of liquid steel transfer from tundish to curved billet mould by open stream and equipped with SEN. Ironmaking \& Steelmaking 2013, 40, 326-334,https://doi.org/10.1179/1743281212Y.0000000053.

36. Matsson, J. An Introduction to ANSYS Fluent. SDC Publications 2020.

37. Miki, Y.; Thomas, B.G. Modeling of inclusion removal in a tundish. Metallurgical and Materials Transactions B 1999, 30, 639-654, https://doi.org/10.1007/s11663-999-0025-6.

38. Taniguchi, S.; Kikuchi, A.; Ise, T.; Shoji, N. Model Experiment on the Coagulation of Inclusion Particles in $\begin{array}{llllll}\text { Liquid Steel. } & \text { ISIJ } & \text { International } & \text { 1996, }\end{array}$ S120,https://doi.org/10.2355/isijinternational.36.Suppl_S117.

39. Johansen, S.T.; Taniguchi, S. Prediction of agglomeration and break-up of inclusions during metal refining, in Light Metals1998, 855-861.

40. Xu, X.; Dey, M.; Qiu, M.; Feng, J.J. Modeling of van der Waals force with smoothed particle hydrodynamics: Application to the rupture of thin liquid films. Applied Mathematical Modelling 2020, 83, 719735,https://doi.org/10.1016/j.apm.2020.03.003.

41. Shrestha, S.; Kuang, S.B.; Yu, A.B.; Zhou, Z.Y. Effect of van der Waals force on bubble dynamics in bubbling fluidized beds of ellipsoidal particles. Chemical Engineering Science 2020, 212, 115343, https://doi.org/10.1016/j.ces.2019.115343.

42. Kushimoto, K.; Ishihara, S.; Pinches, S.; Sesso, M.L.; Usher, S.P.; Franks, G.V.; Kano, J. Development of a method for determining the maximum van der Waals force to analyze dispersion and aggregation of particles in a suspension. Advanced Powder Technology 2020, 31, 2267-2275, https://doi.org/10.1016/j.apt.2020.03.021.

43. Zhao, P.; Li, Y. Correlation between the normal position of a particle on a rough surface and the van der Waals force. Colloids and Surfaces A: Physicochemical and Engineering Aspects 2020, 585, https://doi.org/10.1016/j.colsurfa.2019.124096.

44. Bang-wen, Z.; Kang, D.; Zuosheng, L.; Zhong-ming, R. A mathematical model on coalescence and removal of inclusion particles in continuous casting tundish.Materials Science 2004.

45. Wei, Z.; Bao, Y.; Liu, J.; Gong, W.; Wang, B. Orthogonal analysis of water model study on the optimization of flow control devices in a six-strand tundish. Journal of University of Science and Technology Beijing, Mineral, Metallurgy, Material 2007, 14, 118-124,https://doi.org/10.1016/S1005-8850(07)60024-3.

46. Tolias, P. Non-retarded room temperature Hamaker constants between elemental metals. Surface Science 2020, 700,https://doi.org/10.1016/j.susc.2020.121652.

47. Shen, Q. New insight on critical Hamaker constant of solid materials. Materials Research Bulletin 2021, 133,https://doi.org/10.1016/j.materresbull.2020.111082.

48. Xu, C.-y.; Zhou, T.-T.; Wang, C.-L.; Liu, H.-Y.; Zhang, C.-T.; Hu, F.-N.; Zhao, S.-W.; Geng, Z.-C. Aggregation of polydisperse soil colloidal particles: Dependence of Hamaker constant on particle size. Geoderma 2020, 359,https://doi.org/10.1016/j.geoderma.2019.113999.

49. Chen, C.; Jonsson, L.T.I.; Tilliander, A.; Cheng, G.; Jönsson, P.G. A mathematical modeling study of the influence of small amounts of $\mathrm{KCl}$ solution tracers on mixing in water and residence time distribution of tracers in a continuous flow reactor-metallurgical tundish. Chemical Engineering Science 2015, 137, 914937,https://doi.org/10.1016/j.ces.2015.07.037.

50. Yue, Q.; Zou, Z.-S.; Hou, Q.-F. Aggregation kinetics of inclusions in swirling flow tundish for continuous casting. Journal of Iron and Steel Research International 2010, 17, 6-10, https://doi.org/10.1016/S1006706X(10)60091-X.

51. Dong, J.-h.; Chen, M.; Wang, N. Characteristics of Fluid Flow and Temperature Field of Twin-roll Steel Strip Casting with a Novel-type Delivery System. Journal of Iron and Steel Research International 2015, 22, 885891,https://doi.org/10.1016/S1006-706X(15)30085-6. 
52. Zhou, T.; Li, M.; Li, Q.-L.; Lei, B.; Chenn, Q.-Z.; Zhou, J.-M. Numerical simulation of flow regions in red mud separation thickener's feedwell by analysis of residence-time distribution. Transactions of Nonferrous Metals Society of China 2014, 24, 1117-1124, https://doi.org/10.1016/S1003-6326(14)63170-8.

53. Liu, J.-G.; Yan, H.-C.; Liu, L.; Wang, X.-H. Water Modeling of Optimizing Tundish Flow Field. Journal of Iron and Steel Research International 2007, 14, 13-19, https://doi.org/10.1016/S1006-706X(07)60036-3.

54. Jha, P.K.; Dash, S.K.; Kumar, S. Effect of outlet positions, height of advanced pouring box, and shroud immersion depth on mixing in six strand billet caster tundish. Ironmaking \& Steelmaking 2002, 29, 3646,https://doi.org/10.1179/030192302225005574.

55. Szekely, J.; Ilegbusi, O.J. The Physical and Mathematical Modeling of Tundish Operations. New York: Springer-Verlag, 1989; https://doi.org/10.1007/978-1-4613-9626-0.

56. Siddiqui, M.I.; Kim, M.-H. Two-Phase Numerical Modeling of Grade Intermixing in a Steelmaking Tundish. Metals 2019, 9, 1-14, https://doi.org/10.3390/met9010040.

57. Chen, L.; Chen, J.-S.; Li, Y.-Q.; Wang, S.-B.; Chen, C.J.E.S.W.C. Effects on the fluid flow in a metallurgical tundish-a cfd model study.International Conference on Energy, Environment and Bioengineering (ICEEB 2020)2020, 185,https://doi.org/10.1051/e3sconf/202018504069.

58. Sheng, D.-Y. Mathematical Modelling of Multiphase Flow and Inclusion Behavior in a Single-Strand Tundish. Metals 2020, 10,https://doi.org/10.3390/met10070849.

59. Tkadlečková, M.; Walek, J.; Michalek, K.; Huczala, T. Numerical Analysis of RTD Curves and Inclusions Removal in a Multi-Strand Asymmetric Tundish with Different Configuration of Impact Pad. Metals 2020, 10,1-20, https://doi.org/10.3390/met10070849.

60. Maulik, R.; Sharma, H.; Patel, S.; Lusch, B.; Jennings, E. A turbulent eddy-viscosity surrogate modeling framework for Reynolds-averaged Navier-Stokes simulations. Computers \& Fluids 2021, 227,https://doi.org/10.1016/j.compfluid.2020.104777.

61. Chang, S.; Huang, W.; Zou, Z.; Li, B.; Guthrie, R.I.L. Motion behavior of micro-bubbles in a delta shape tundish using impact pad. Powder Technology 2020, 367, 296304,https://doi.org/10.1016/j.powtec.2020.03.051 